\title{
Enhancing Workplace Safety Culture in the Mining Industry in Ghana
}

\author{
Felix Kwame Opoku \\ (Corresponding author) \\ University of Cape Coast, Ghana \\ felix.opoku@ucc.edu.gh \\ Isaac Kosi \\ University of Cape Coast, Ghana \\ ikosi@ucc.edu.gh \\ Dominic Degraft-Arthur \\ University for Development Studies, Ghana \\ darthur@uds.edu.gh \\ DOI//http://dx.doi.org/10.4314/gjds.v17i2.2
}

\begin{abstract}
The paper concerns organisational safety culture and how it may be applied to reduce employee accidents in the mining industry in Ghana. A sample of 340 managerial workers of three mining companies in the Tarkwa Nsuaem Municipality was selected using the simple random sampling technique. Data for the study was gathered using a survey questionnaire. The Structural Equation Modelling analysis technique was performed to establish the relationship between safety culture and each of the five dimensions of workplace safety (work safety, management safety practices, safety programmes, supervisor safety and co-worker safety). It was found that safety culture is a significant positive predictor of work safety $\left(R^{2}=0.039\right)$, management safety practices $\left(R^{2}=0.272\right)$, safety programmes $\left(R^{2}=0.159\right)$, co-worker safety $\left(R^{2}=0.225\right)$ and supervisor safety $\left(R^{2}=\right.$ 0.199). The study concluded that workplace safety can be improved by enhancing the safety culture in the mining industry in Ghana. The study recommends that in order to curb the incidence and occurrence of accidents and injuries in the mining industry in Ghana, Human Resource (HR) managers should lay more emphasis on ways that would enhance the safety culture of all employees in the industry.
\end{abstract}

Keywords: Safety Culture, Mining Industry, Workplace Safety, Industrial Accidents, Ghana 


\section{INTRODUCTION}

Following the 2010 National Mining Policy of Ghana, there has been a significant flow of external investment in the mining sector of Ghana (Ghana Mineral Commission, 2014). As a result, the mining industry contributed twenty-seven per cent (27\%) of the total tax revenue in 2012, with gold alone recording approximately $\$ 5.6$ billion from 4.3 million ounces (Kyeremateng-Amoah \& Clarke, 2015). In 2014, the industry also contributed $\mathrm{GH} \$ 1.24$ billion tax revenue to the government and employed 12,148 Ghanaians (Long et al., 2015). The increase in investment and mining activities did not only present economic opportunities for Ghana but also brought some occupational health and safety challenges (Kyeremateng-Amoah \& Clarke, 2015). It is reported that staff of the mining sector are frequently at risk of occupational injury due to the abundance of risk factors such as rock falls, fire explosions, mobile equipment accidents, entrapments and electrocutions (Stemn, 2018). A report from the Inspectorate Division of the Ghana Minerals Commission (2014) has shown that while in 2008 accidents that caused both minor injuries and no injuries were 58, the number increased to 1,201 in 2014. Overall workplace injury also increased from 9,664 cases in 2017 to 18,070 cases in 2018 (Ghana Mineral Commission, 2019).

According to the Inspectorate Division of the Ghana Minerals Commission, the average number of work-related accidents in the mining sector from 2008 to 2014 was 333 cases per year. The non-casualty incident for the same period was also 1,915 cases (Ghana Mineral Commission, 2019). Though the accident trend for this period does not include higher fatalities, it is still a problem because several scholars (Kyeremateng-Amoah \& Clarke, 2015; Goetsch, 2005) have indicated that the higher the near-misses, the more the likelihood that fatal accident will occur. Similarly, Heinrich (1931) has shown that anytime an accident causes a major injury, there could be 29 accidents, causing minor injuries and 300 accidents that cause no injuries. In line with Heinrich's (1931) principle, it can be argued that the Ghana mining industry which currently accumulates minor accidents is likely to record some fatal accidents in the near future if appropriate measures are not put in place. Heinrich's (1931) principle may also apply to other African countries like South Africa, Tanzania and Congo. In South Africa for instance, between January 2004 and June 2008, there were 5,822 accidents of which almost 90 per cent were generally classified as high potential incidents, less than $1 \%$ being fatalities, $2 \%$ being lost time accidents and 7.7\% described as non-reportable incidents (Steward, Bezuidenhout \& Bischoff, 2020). A study in the small-scale mining community of 
Geita in Tanzania showed that there are about 11 fatalities of mining accidents in the community per year, owing to tunnel collapses. Another study of ASGM community in the Democratic Republic of Congo showed that 392 accidents occurred during the 12 months in 2016 (Elgstrand et al., 2017).

Given the above alarming rates of injuries and industrial accidents in the industry, various studies have been conducted to identify the major causes of these injuries and how they can be curbed. For instance, Kyeremateng-Amoah and Clarke (2015) examined the injury state of artisanal and small-scale gold miners in Ghana. They found that the most common injuries included fractures (30.5\%), contusions (29.1\%) and lacerations (14.0\%). Stemn (2018) also examined the injury state of firms in the Ghana mining industry and found that the mechanisation of operations without prior safety training for employees accounted significantly to the risks involved in their operation. According to Stemn (2018), the rate of mining accidents in the country far exceeds those of major mining countries including Australia, South Africa and the U.S. Stemn et al. (2019) investigated the maturity of investigations into the industrial accidents of the Ghana mining industry. It was found that higher maturity scores were associated with low incidence rate mines than high incidence rate mines.

Despite significant research conducted over the last few years, there is still an upsurge in the rate and brutality of mining accidents in Ghana (Stemn et al., 2019; Stemn, 2018; Bansah et al., 2016). Nevertheless, while earlier studies focused on the frequency and intensity of these accidents, a few (Umar-Faruk et al., 2015; Lu \& Tsai, 2010; Cheyne et al., 1999) have paid attention to how these accidents can be mitigated through the general attitude and behaviours of employees in the mining industry in Ghana. Although there is evidence to show that workplace accidents in the Ghana mining industry have been tackled from the behavioural and social perspective, none of these works investigated the effect of safety culture on workplace safety in the Ghanaian mining industry. The implementation of safety culture in the mining industry is essential because previous studies have shown that workplace safety significantly influences organisational outcomes, including safety performance (Stemn et al., 2019) and organisational commitment (Amponsah-Tawiah \& Mensah, 2016). Safety culture is also related to turnover intention (Amponsah-Tawiah et al., 2015) and employees' safety experience (Amponsah-Tawiah et al., 2013). Hence, given the substantial investment inflows and the significant economic contribution the industry has made to the Ghanaian economy in the past, and the negative consequences of accidents in that industry, an examination of safety culture and its effect on workplace safety in the Ghana 
mining industry is considered imperative. The rest of the report is set out as follows: the second part of the study covers the literature review. The methods and procedures used to carry out the study are presented in the third section. The fourth section focuses on the results of the study. The fifth section is devoted to the discussions of the study. The last section presents the conclusion, recommendations and practical implications of the study.

\section{LITERATURE REVIEW}

\section{Concept of Safety Culture}

The U.S. Nuclear Regulatory Commission (2011) defines safety culture as an organisation's collective commitment, by leaders and individuals, to emphasise safety as an overriding priority to competing goals and other considerations to ensure protection of people and the environment (Sehgal, 2012). Concerning the workplace, safety culture was first discussed by the International Nuclear Safety Advisory Group of International Atomic Energy Agency in their analysis of the Chernobyl disaster (Sehgal, 2012). As a concept, safety culture originated from earlier philosophical works in anthropology, sociology and organisational psychology. However, while earlier works in safety culture originally described the inadequacies of safety management systems, Bell (2007) argued that safety culture is now applied to social behaviours at the individual employee level.

Reason (1994) identified five factors which contribute to the development of stable and robust safety culture: (a) an informed safety, (b) a reporting safety, (c) a learning safety, (d) a flexible safety and (e) a just safety. Informed safety culture is one in which organisational members understand and respect their operational hazards, and are therefore conversant with the many ways in which the system's defences can be breached or bypassed. In a reporting safety culture, group or organisational members feel free to report safety concerns without fear or blame. For a learning safety culture, members learn from previous mistakes and make changes to unsafe conditions. In contrast, inflexible safety culture, the organisation, if faced by a dynamic and demanding task environment, is capable of reconfiguring the chain of command. In a just safety culture, organisational members understand the boundary between acceptable and unacceptable behaviours.

In terms of addressing workplace accidents, safety culture is an alternative mechanism (Seo, 2005). In the past, industrial accidents were blamed on the technical and human aspects of the organisation (Glendon et al., 2006; Seo, 
2005). At that time, attention was drawn mainly on technological malfunctions from defective equipment, the faulty layout of the plant, inadequate safety devices, unsafe storage systems as well as the looming danger of industrial work environment, characterised by a chunk of hand lift trucks, heavily loaded vehicles, wheel-barrows and electric drop lights, which according to Goetsch (2005) caused a third of all industrial accidents (Stemn, 2018; Ceylan, 2013). Besides, attention has also drawn to unsafe acts on the part of employees, including failure to use protective attire and careless handling of machines and equipment (Stemn et al., 2019; Stemn, 2018). At the turn of the $19^{\text {th }}$ Century, industrial theorists found that workplace accidents occurred within cultural and social contexts (Stemn et al., 2019; Stemn, 2018). According to these theorists, organisational factors were equally important as technical and human factors in the fight against workplace accidents. Safety culture then became the new research interest (Bansah et al., 2016).

\section{Models of Safety Culture}

While there are several safety models, including Reason's safety pyramid model (1990), Geller's (1994) total safety model, Guldenmund's (2000) framework for safety culture, this study is built on the Cooper (2002) Business Process Model of safety culture. The Business Process Model holds that to ensure safety at the workplace, the values, beliefs, assumptions, behaviours and safety management systems, otherwise called the "Inputs" must be transformed in line with the safety goals and expectations of the company and safety practices of management (i.e. Output). This will, in turn, lead to a safety culture product (Outcome). According to Cooper (2002), the link between input and output factors is mediated by supervisor safety, management safety, co-worker safety and safety programmes (Aytac \& Dursun, 2012). Adapting this model, the researchers argue that safety dimensions can strategically be employed to reduce accidents and improve workplace safety in Ghana, as presented in Figure 1. 


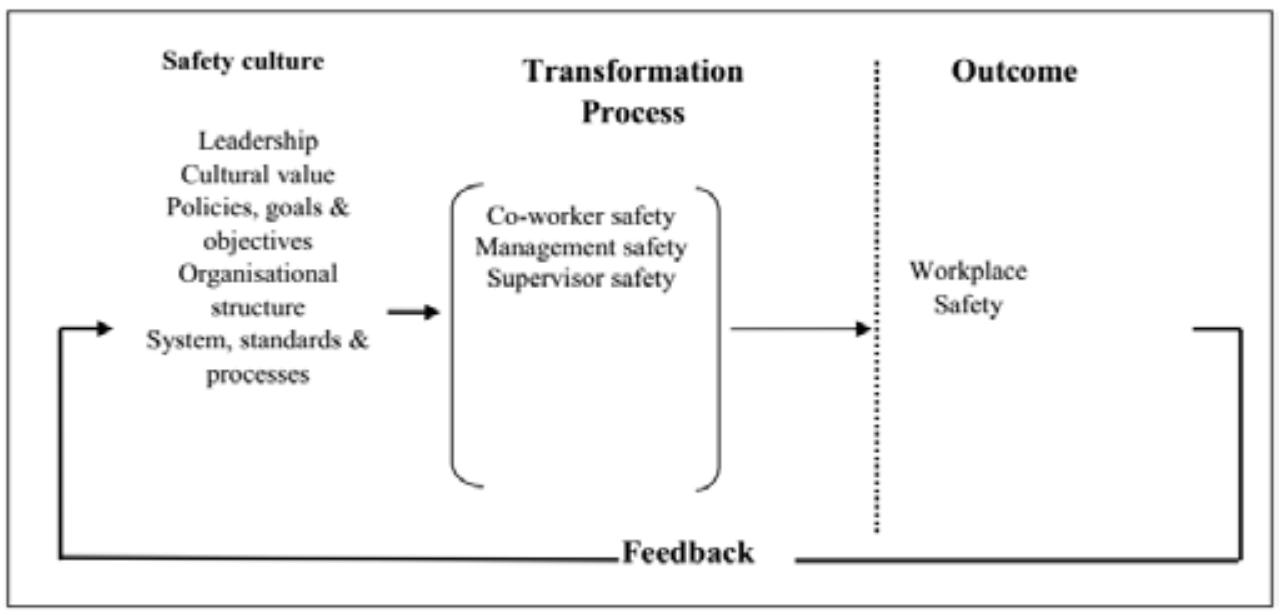

Figure 1: Business process model of safety culture

Source: Adapted from Cooper (2002).

\section{Ghanaian Mining Sector Health and Safety Issues}

The Ghana mining industry is bereft with its problems and challenges. The Inspectorate Division of the Minerals Commission on occupational health has shown that between 2000 and 2004, problems caused by mining activities included malaria and respiratory tract infection, which together caused outpatient morbidity among members in the mining communities (Bansah et al., 2016; Standing, 2014). The use of illicit drugs such as marijuana and cocaine as stimulants for hardworking has also increased significantly, especially among illegal and smallscale miners in Ghana (Standing, 2014). The mining towns in Ghana have been harbouring commercial sex workers. The industry has again created other social vices such as theft, murder and rape (Amponsah-Tawiah \& Dartey-Baah, 2011). In this study, however, the focus is on workplace accidents as presented in Table 1. 
Table 1: Seven-year accident trend in the mining sector in Ghana (2009 - 2015)

\begin{tabular}{|l|c|c|c|c|c|c|c|c|}
\hline \multirow{2}{*}{ Accidents } & \multicolumn{9}{|l|}{ Number of accidents/incidents } \\
\cline { 2 - 11 } & $\mathbf{2 0 0 9}$ & $\mathbf{2 0 1 0}$ & $\mathbf{2 0 1 1}$ & $\mathbf{2 0 1 2}$ & $\mathbf{2 0 1 3}$ & $\mathbf{2 0 1 4}$ & $\mathbf{2 0 1 5}$ & Total \\
\hline Fatal accidents & 4 & 4 & 8 & 8 & 4 & 6 & 4 & 54 \\
\hline $\begin{array}{l}\text { Serious } \\
\text { accidents }\end{array}$ & 47 & 39 & 33 & 31 & 13 & 20 & 19 & 235 \\
\hline Minor injuries & 159 & 176 & 153 & 188 & 138 & 113 & 155 & 1143 \\
\hline Non-casual & 0 & 0 & 191 & 281 & 348 & 1088 & 400 & 2315 \\
\hline Non-employee & 4 & 0 & 2 & 5 & 3 & 1 & 4 & 19 \\
\hline \multicolumn{1}{|c|}{ Total } & 214 & 219 & 387 & 513 & 506 & 1228 & 608 & 3766 \\
\hline
\end{tabular}

Source: Adapted from the Inspectorate Division of the Ghana Minerals Commission, 2016.

As in Table 1, a total of 3,766 accidents were recorded between 2008 and 2015; averaging about 471 accidents per year. Besides, 2,315 non-casualty (near misses) accidents were recorded within the same period. These high rates of non-casualty accidents are alarming because the more non-casualty accidents there are, the more likely that fatal accident will also occur (Bansah et al., 2016; Standing, 2014).

\section{EMPIRICAL STUDIES ON BENEFITS AND FACTORS OF WORKPLACE CULTURE}

Safety culture plays an important role in improving workplace safety dimensions such as work safety, co-worker safety, management safety practices, supervisor safety and safety programmes (Årstad \& Aven, 2017). Hassan and Abdullah (2009) confirmed this when they argued that the most fundamental reason for improving safety culture in the organisation is the realisation that employee attitudes and behaviours are crucial to the workplace and the work itself. Put differently; safety culture has been found to be highly related to most of the behavioural outcomes at the workplace (Zou, 2011). Whilst, there are several behavioural factors; this study focuses on the five workplace safety dimensions, including work safety, co-worker safety, management safety practices, supervisor safety and safety programmes.

Previous studies have shown that cultural change in organisations is fundamental in improving work safety and delivery (Zou, 2011; Clarke, 2003). Clarke (2003), for instance, argued that when the norms and values of organisational members are built into company safety policies and procedures, and properly implemented, work safety would be achieved. Zou (2011) established that safety work requires employees to be equipped with the most appropriate beliefs, values and attitudes. These reviews show that safety work greatly depends on positive safety culture, which in turn depends on positive attitudes by both superiors and subordinates. 
Safety culture affects not only safety programmes but co-worker safety as well. Co-workers play an essential role in promoting workplace safety attitudes and behaviours. Tucker, Chmiel, Turner, Hershcovis and Stride (2008) claim that support from co-workers has the propensity to cause other employees to enhance workplace safety. The positive safety behaviours that co-workers exhibit may be influenced by safety culture. Indeed, Pater (2015), points out that safety culture influences co-worker behaviours by encouraging them to indulge in safe work practices and shared responsibility. Pronovost and Sexton (2005) also argue that in a safe culture, worker actions are directed at the organisation-wide commitment to safety in which individual worker supports safety norms and those of their coworkers.

Safety culture has also been found to be strongly related to safety management practices. Scholars such as Årstad and Aven (2017) and Gnoni and Saleh (2017) posited that managers could ensure effective and efficient safety culture if they can identify hazards earlier so that appropriate measures can be put in place to train and empower the workforce adequately. In this regard, work processes can be designed and carried out in a manner that delivers more consistent safety conditions and performance. Gnoni and Saleh (2017) claim that accidents do not just happen - near-miss events usually precede accident events. Thus, with proper management practices and strong leadership, specific strategies can be formulated and implemented in order to prevent their occurrence. Past studies indicate that there is a positive link between safety culture and safety programmes (AmponsahTawiahn et al., 2015; Pater, 2015; Zivkovic \& Ivanova, 2016). For instance, according to Zivkovic and Ivanova (2016), amid a proper safety culture, broad organisational safety programmes that aim at continuously improving safety management systems are developed and implemented. Safety programmes which usually enunciate safety principles with top-down approach often create self-sustaining environments (Hagge et al., 2016; Kim et al., 2016).

Much work has not been done concerning how safety culture affects supervisor safety. It can only be inferred from the submission by Misnan and Mohammed (2007) that safety culture can promote flexible and efficient safety supervision system in the construction industry in which construction sites are exposed continuously to safety risk. Based on the empirical review, five hypotheses have been formulated to guide this study:

H1: Safety culture has positive effect on work safety

$\mathrm{H}$ : Safety culture has positive effect on management safety practices 
H3: Safety culture has positive effect on safety programmes

$\mathrm{H}_{4}$ : Safety culture has positive effect on co-worker safety

$\mathrm{H}_{5}$ : Safety culture has positive effect on supervisor safety

\section{METHODOLOGY}

\section{Research Design}

The study adopted a quantitative research design. According to Babbie (2007), quantitative research is most appropriate when the emphasis is on measuring variables and testing hypotheses that are linked to general causal explanations.

\section{Population, Sampling, Data Collection and Analysis}

The population of this study comprised all the 3,980 non-managerial employees of the three large scale mining companies in the Tarkwa Nsuaem Municipality. Table 2 shows the population of each company, the total sample size and the sample size of each company. The computation of the sample sizes for the companies was based on simple proportion.

Table 2: Distribution of respondents in the three selected companies

\begin{tabular}{|l|c|c|}
\hline \multicolumn{1}{|c|}{ Mining companies } & Total & Sample \\
\hline Goldfield Ghana Limited & 1,400 & 123 \\
\hline Anglogold Ashanti & 1,700 & 149 \\
\hline Ghana Manganese Company & 880 & 78 \\
\hline Total & 3,980 & 350 \\
\hline
\end{tabular}

Source: Ghana Minerals Commission (2018).

A survey questionnaire was administered to the 350 sample members. However, 340 completed responses were received, representing 97 per cent response rate. The Structural Equation Modelling (SEM-PLS) technique was performed to establish the relationship between safety culture and the five dimensions of workplace safety. The technique is appropriate for this study because it combines the advantages of several traditional multivariate procedures such as the factor analysis, regression analysis, discriminant analysis and canonical correlation (Haenlein and Kaplan, 2004). Thus, the model is chosen to ensure that sufficient levels of validity and reliability are satisfied in the study. The Cronbach alpha ( $\mathrm{CA}>0.70)$ and Composite Reliability (CR) were used to measure the reliability of the survey items. The validity 
of the results was also measured, using the convergent and discriminant validity measures (Rezaei, 2015).

\section{Measurement of Variables}

The scales for measuring each variable were adopted from previously validated measures. Safety culture was measured using the measurement scales of Changwon (2016). The items were grouped into six dimensions: leadership, goals and policies, culture and values, organisational structure, employee engagement and behaviours, systems and standards and process. Workplace safety was measured using Hayes et al. (1998) Workplace Safety Scale to assess employee perception of safety in the organisation. The scales measure five dimensions of workplace safety: work safety; co-workers' safety; supervisor safety; management's commitment to safety; and satisfaction with the safety programme. The items were on a five-point Likert Scale with anchors $1=$ Least Agreement to 5 = highest Agreement .

\section{Common Method Bias}

Common Method Bias (CMB) is a measurement error which can occur due to selfreport measures (Podsakoff et al., 2012). One possible cause of CMB is the implicit social desirability or answering survey questions in a particularly desirable way, causing indicators to share common variation (Kock \& Lynn, 2012). This bias can lead to unsound conclusions because it can inflate or deflate a given relationship among variables (Doty \& Glick, 1998). The Harman's Single Factor Test, which, according to Podsakoff et al. (2012), is the most widely used test in the literature to control against $\mathrm{CMB}$ was conducted in this study. In line with this test, all items that measured variables in the study were entered into exploratory factor analysis, with a principal axis factoring analysis, limiting the extraction to just one factor. The first factor accounted for $31.738 \%$ of the variance. In line with Mat-Roni (2014), this indicates that no single factor emerged and so no one general factor accounted for most of the covariance among the latent factors. Therefore, CMB does not affect the results of this study.

\section{PLS-SEM Analysis}

The results of the PLS-SEM analysis in this study are presented in line with the proposal of Hair et al. (2019). The presentation begins with an assessment of the measurement model and a final assessment of the structural model. 


\section{Measurement Model Assessment}

The first step in the measurement model involves examining the indicator loadings of all the constructs in this study. Following this was the assessment of internal consistency reliability, using both composite reliability (CR) and Cronbach's alpha (CA). In the third step, the convergent validity of each construct was assessed using the Average Variance Extracted (AVE). In the final step, discriminant validity was assessed, using both Fornell-Larcker criterion and the Heterotrait-Monotrait Ratio (HTMT). For the indicator loadings of all constructs, Table 3 shows that almost all the loadings were above the threshold of 0.7 . The few items loading above 0.5 but less than 0.7 were not deleted to improve the reliability of the constructs. Hair et al. (2014) have argued that a measurement model would be considered appropriate if its indicators loaded above 0.70 on the latent variables or "between 0.4 and 0.7 " in circumstances where removing them would not lead to an increase in the reliability of the model. 
Table 3: Measurement model results

\begin{tabular}{|c|c|c|c|c|}
\hline Items & Loadings & CA & CR & AVE \\
\hline CO-WORKER SAFETY & & 0.882 & 0.905 & 0.548 \\
\hline CWS10 & 0.751 & & & \\
\hline $\mathrm{CWS}_{3}$ & 0.718 & & & \\
\hline $\mathrm{CWS}_{4}$ & 0.800 & & & \\
\hline $\mathrm{CWS}_{5}$ & 0.784 & & & \\
\hline CWS6 & 0.821 & & & \\
\hline $\mathrm{CWS}_{7}$ & 0.594 & & & \\
\hline CWS8 & 0.626 & & & \\
\hline CWS9 & 0.792 & & & \\
\hline MANAGERIAL SAFETY PRACTICES & & 0.865 & 0.896 & 0.555 \\
\hline $\mathrm{MSP}_{1}$ & 0.773 & & & \\
\hline $\mathrm{MSP}_{10}$ & 0.591 & & & \\
\hline $\mathrm{MSP}_{2}$ & 0.809 & & & \\
\hline $\mathrm{MSP}_{3}$ & 0.741 & & & \\
\hline $\mathrm{MSP}_{5}$ & 0.788 & & & \\
\hline MSP6 & 0.747 & & & \\
\hline $\mathrm{MSP}_{7}$ & 0.744 & & & \\
\hline SAFETY CULTURE & & 0.882 & 0.905 & 0.514 \\
\hline GPI10 & 0.684 & & & \\
\hline $\mathrm{GPI} 2$ & 0.697 & & & \\
\hline $\mathrm{OS}_{14}$ & 0.748 & & & \\
\hline $\mathrm{OS}_{16}$ & 0.720 & & & \\
\hline $\mathrm{OS}_{2}$ & 0.689 & & & \\
\hline OS23 & 0.710 & & & \\
\hline OS6 & 0.723 & & & \\
\hline $\mathrm{OS}_{7}$ & 0.740 & & & \\
\hline OS8 & 0.738 & & & \\
\hline SAFETY PROGRAMMES & & 0.850 & 0.887 & 0.531 \\
\hline $\mathrm{SP}_{1}$ & 0.662 & & & \\
\hline $\mathrm{SP}_{2}$ & 0.762 & & & \\
\hline $\mathrm{SP}_{3}$ & 0.825 & & & \\
\hline $\mathrm{SP}_{4}$ & 0.790 & & & \\
\hline SP6 & 0.646 & & & \\
\hline $\mathrm{SP}_{7}$ & 0.775 & & & \\
\hline SP8 & 0.614 & & & \\
\hline SUPERVISOR SAFETY & & 0.869 & 0.897 & 0.522 \\
\hline $\mathrm{SS}_{1}$ & 0.723 & & & \\
\hline $\mathrm{SS}_{10}$ & 0.628 & & & \\
\hline $\mathrm{SS}_{2}$ & 0.766 & & & \\
\hline $\mathrm{SS}_{3}$ & 0.783 & & & \\
\hline $\mathrm{SS}_{5}$ & 0.671 & & & \\
\hline SS6 & 0.762 & & & \\
\hline $\mathrm{SS}_{7}$ & 0.723 & & & \\
\hline SS8 & 0.708 & & & \\
\hline WORK SAFETY & & 0.790 & 0.790 & 0.570 \\
\hline $\mathrm{WS}_{3}$ & 0.566 & & & \\
\hline $\mathrm{WS}_{4}$ & 0.661 & & & \\
\hline $\mathrm{WS}_{1}$ & 0.977 & & & \\
\hline
\end{tabular}


The internal consistency reliability results presented in Table 3, indicate that the Cronbach Alpha values range from 0.790 to 0.882 . The internal consistency reliability was also measured using the composite reliability, which, according to Hair et al. (2019) are more conservative than the Cronbach Alpha. Composite reliability values for the constructs in this study also ranged from 0.790 to 0.905 . The values are way higher than the threshold of 0.7 , indicating a high level of reliability (Jöreskog's, 1971). Convergent validity was also assessed in this study, using the Average Variance Extracted (AVE). According to Hair et al. (2019), an Average Variance Extracted value of 0.50 or higher indicates that the construct accounts for 50 per cent or more of the variance of the items that make up the construct. The AVE values for the constructs in this study ranged from 0.514 to 0.570 . Thus, indicating that the constructs converge to explain the variance of its items.

The discriminant validity for this study was assessed using both the Fornell-Larcker criterion and the Heterotrait-Monotrait Ratio. Fornell and Larcker (1981) proposed that the square root of each construct's AVE must be higher than its correlation with any other variable in the model. Using this criterion, the results in Table 4 were obtained. As presented in Table 4, the square roots of the AVE values (in bold) are higher than any inter-construct correlation value. This shows that the constructs are distinct from each other. Henseler, Ringle, and Sarstedt (2015) indicate that Fornell-Lacker criterion does not work well when indicator loadings are close.

Table 4: Fornell-Larcker Criterion

\begin{tabular}{|l|c|c|c|c|c|c|}
\hline \multicolumn{1}{|c|}{ Constructs } & $\mathbf{1}$ & $\mathbf{2}$ & $\mathbf{3}$ & $\mathbf{4}$ & $\mathbf{5}$ & $\mathbf{5}$ \\
\hline 1. Co-worker safety & $\mathbf{0 . 7 4}$ & & & & & \\
\hline 2. Management safety practices & 0.45 & $\mathbf{0 . 7 5}$ & & & & \\
\hline 3. Safety culture & 0.47 & 0.52 & $\mathbf{0 . 7 2}$ & & & \\
\hline 4. Safety programmes & 0.34 & 0.54 & 0.40 & $\mathbf{0 . 7 3}$ & & \\
\hline 5. supervisor safety & 0.47 & 0.62 & 0.45 & 0.53 & $\mathbf{0 . 7 2}$ & \\
\hline 6. Work safety & 0.04 & 0.24 & 0.20 & 0.35 & 0.34 & $\mathbf{0 . 7 6}$ \\
\hline
\end{tabular}

Diagonal values in bold = square root of AVE; off diagonal elements $=$ correlation between constructs.

Another approach used to discriminant validity was the Heterotrait-Monotrait Ratio (HTMT). In a well-fitted model, Henseler et al. (2015) proposed that HTMT values should be below 0.85 for reflective constructs to measure discriminant validity accurately. The results of the HTMT are shown in Table 5. As in Table 5, the Heterotrait-Monotrait Ratio values for each construct is well below the threshold 
of 0.85 , indicating that discriminant validity is met and that the constructs are empirically different from each other in the model.

Table 5: Heterotrait-Monotrait Ratio (HTMT)

\begin{tabular}{|l|c|c|c|c|c|}
\hline \multicolumn{1}{|c|}{ Constructs } & $\mathbf{1}$ & $\mathbf{2}$ & $\mathbf{3}$ & $\mathbf{4}$ & $\mathbf{5}$ \\
\hline 1. Co-worker safety & & & & & \\
\hline 2. Management safety & 0.501 & & & & \\
\hline 3. Safety culture & 0.507 & 0.574 & & & \\
\hline 4. Safety programmes & 0.379 & 0.623 & 0.452 & & \\
\hline 5. Supervisor safety & 0.506 & 0.696 & 0.494 & 0.616 & \\
\hline 6. Work safety & 0.185 & 0.217 & 0.170 & 0.369 & 0.291 \\
\hline
\end{tabular}

\section{RESULTS}

\section{Demographic Characteristics of Respondents}

This section provides the demographic characteristics of respondents as in Table 6.

Table 6: Demographic characteristics of respondents

\begin{tabular}{|l|l|c|c|}
\hline \multicolumn{1}{|c|}{ Profile of Respondents } & \multicolumn{1}{|c|}{ Statement } & Frequency & $\%$ \\
\hline Gender & Male & 290 & 85.29 \\
\hline & Female & 50 & 14.71 \\
\hline Years of Service & $1-5$ & 165 & 48.53 \\
\hline & $6-10$ & 135 & 39.71 \\
\hline & $11+$ & 40 & 11.76 \\
\hline Level of education & University Degrees & 98 & 28.82 \\
\hline & Diploma/Technical & 161 & 47.35 \\
\hline & Senior High School & 70 & 20.59 \\
\hline & Junior High School & 11 & 3.24 \\
\hline
\end{tabular}

The demographic features of interest about the respondents included gender, length of service and academic qualifications. Out of the 340 valid responses, (85.29\%) are males while (14.71\%) were females. The results indicate the usual male-domination of employees in dangerous occupations in the developing economies. The results revealed that majority of the respondents (48.53\%) had worked for between $1-5$ years, whereas $40(11.76 \%)$ have had more than eleven years of experience. The remaining respondents $(39.71 \%)$ indicated that they have worked in the industry for a period of six (6) to ten (10) years. Most of the respondents (47.35\%) have acquired the Diploma/Technical qualifications whiles only 3.24\% have completed Junior High 
School. 28.82\% of the employee had a University Degree, while the remaining 20.59\% had Senior High School Certificates.

\section{Structural Model Assessment}

The structural model was assessed having met all the measurement model assessment criteria. The standard assessment criteria involved in assessing the structural model in PLS-SEM include the coefficient of determination $\left(\mathrm{R}^{2}\right)$, the blindfolding-based cross-validated redundancy measure $\mathrm{Q}^{2}$, the effect size $\left(\mathrm{f}^{2}\right)$, and the statistical significance and relevance of the path coefficients as presented in Table 7.

Table 7: Coefficient of Determination and $Q^{2}$

\begin{tabular}{|l|l|l|c|}
\hline \multicolumn{1}{|c|}{ Endogenous Variable } & VIF & R $^{2}$ & Adjusted R $^{2}$ \\
\hline Co-worker safety & 1.000 & 0.225 & 0.222 \\
\hline Management safety practices & 1.000 & 0.272 & 0.270 \\
\hline Safety programmes & 1.000 & 0.159 & 0.157 \\
\hline Supervisor safety & 1.000 & 0.199 & 0.196 \\
\hline Work safety & 1.000 & 0.039 & 0.037 \\
\hline
\end{tabular}

Table 6 shows the assessment of the structural results began with an examination of collinearity, using the Variance Inflation Factor (VIF) values. For Hair, Risher, Sarstedt and Ringle (2019), the VIF values must be closer to 3 or lower, in order to indicate the absence of collinearity. From Table 6, the VIF values in this study are well below 3 , indicating no collinearity. The $\mathrm{R}^{2}$ values of the endogenous constructs were also examined. The results, as in Table 6, show that Safety culture (the exogenous construct) accounts for $22.5 \%$ of the variation in Co-worker safety. It also accounts for $27.2 \%$ of the variation in Management safety practices and $15.9 \%$ of the variance in safety programmes. Also, the results in Table 6 show that $19.9 \%$ of the variance in supervisor safety is accounted for by Safety Culture. Table 6 further indicates that $3.9 \%$ of the variance in work safety is accounted for by safety culture. Indicating that safety culture has explanatory power on workplace safety. According to Raithel, Sarstedt, Scharf and Schwaiger (2012), an acceptable value of $\mathrm{R}^{2}$ is based on context. The path model (Figure 2) indicates that there are five hypothesised paths considered in this study, emphasising the relationship between the five dimensions of workplace safety and safety culture. 


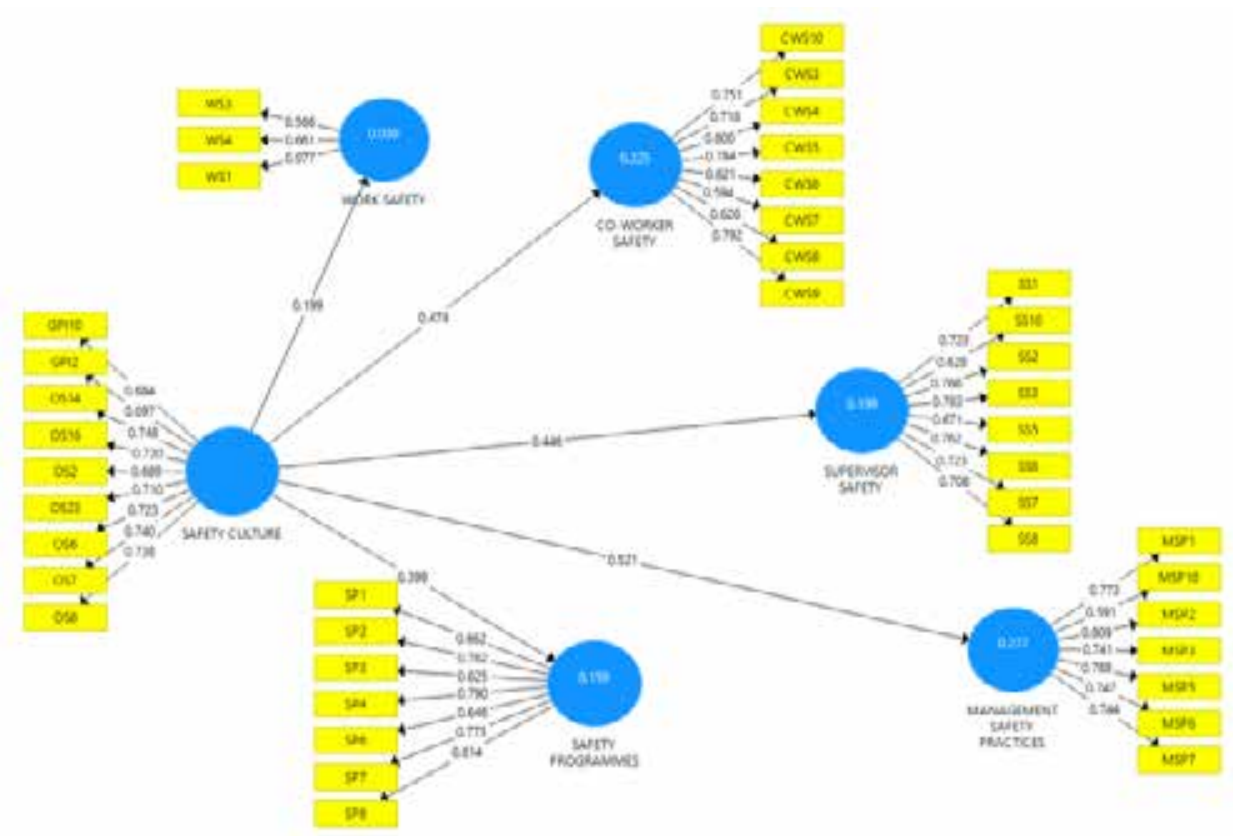

\section{Figure 2: A path model}

The significance of the path, as indicated in Figure 2, are assessed in Table 7. The rank order of the path coefficient indicates Safety culture's relevance in predicting each endogenous variable. Table 7 indicates that safety culture has the largest significant positive effect on Management safety practices (0.521, $\mathrm{p}=0.000$ ). The next significant predictive influence of Safety culture is on co-worker safety (o.474, $\mathrm{p}=0.000$ ). Following this is the effect of safety culture on supervisor safety (o.446, $\mathrm{p}=0.000)$. The results indicate that safety culture has a positive significant predictive influence on supervisor safety. The results indicate that safety culture has a significant positive influence on safety programmes (0.399, p = o.ooo), and work safety (0.199, $\mathrm{p}=0.0032$ ). In summary, the results show that safety culture has a significant positive influence on all the dimensions of workplace safety, as in Table 7 . 
Table 7: Structural model results

\begin{tabular}{|l|c|c|c|c|c|l|}
\hline Structural Path & $\begin{array}{l}\text { PathCoeff. } \\
(\beta)\end{array}$ & $\begin{array}{c}\text { T } \\
\text { Statistics }\end{array}$ & P-Value & $\mathbf{f}^{2}$ & $\mathbf{Q}^{2}$ & Conclusion \\
\hline $\begin{array}{l}\text { safety culture } \\
\text { co-worker safety }\end{array}$ & 0.474 & 11.144 & 0.000 & 0.290 & 0.111 & Supported \\
\hline $\begin{array}{l}\text { safety culture } \\
\text { management safety } \\
\text { practices }\end{array}$ & 0.521 & 11.317 & 0.000 & 0.373 & 0.142 & Supported \\
\hline $\begin{array}{l}\text { safety culture safety } \\
\text { programmes }\end{array}$ & 0.399 & 8.226 & 0.000 & 0.190 & 0.080 & Supported \\
\hline $\begin{array}{l}\text { safety culture } \\
\text { supervisor safety }\end{array}$ & 0.446 & 9.545 & 0.000 & 0.248 & 0.095 & Supported \\
\hline $\begin{array}{l}\text { safety culture work } \\
\text { safety }\end{array}$ & 0.199 & 2.141 & 0.032 & 0.041 & 0.007 & Supported \\
\hline
\end{tabular}

The $f^{2}$ effect size was examined to determine the contribution of the exogenous construct (Safety culture) to each endogenous construct. All values that are higher than 0.02, 0.15, and 0.35 have small, medium, and large $f^{2}$ effect sizes (Cohen, 1988). The results from Table 7 show that Safety culture has a large effect on management safety practices (0.373) and medium effect size on co-worker safety (0.290), Supervisor safety (0.248) and safety programmes (0.190). However, the results indicate that safety culture has a small effect on work safety (0.041). Furthermore, the predictive relevance of the model was assessed using the $Q^{2}$ value (Geisser, 1974; Stone, 1974). Hair et al. (2019) propose that $\mathrm{Q}^{2}$ above o indicate predictive relevance. The predictive relevance of all the endogenous constructs is above the threshold of zero, supporting the model's predictive accuracy. From Table 7, it can be concluded that Safety culture has a significant positive influence on all the dimensions of workplace safety within the mining industry in Ghana.

\section{DISCUSSION}

The study examined the contribution of safety culture to workplace safety in the mining industry in Ghana. The discussions are based on five relationships as captured in the hypothesis.

\section{Relationship between Safety Culture and Work Safety}

The first hypothesis was formulated to show a relationship between safety culture and work safety. The results revealed that safety culture is a significant positive predictor of work safety in the mining industry in Ghana $(\beta=0.199 ; \mathrm{t}=2.141 ; \mathrm{p}=$ 
0.032: $\mathrm{p}<0.05$ ). The results indicate that a unit increase in safety culture causes 0.199 increase in work safety. However, though safety culture is empirically relevant to improving work safety in the mining industry, it has only a small effect on work safety (see Table 7). The coefficient of determination between safety culture and work safety was $\mathrm{R}^{2}=0.039$, showing that the variation in safety culture explains $3.9 \%$ of the variation in work safety. Thus, safety culture accounts for a very weak variance in work safety. The aspect of work safety that are improved as a result of changes in safety culture include the belief that the work performed by employees in the industry are no more dangerous, hazardous or risky. These results support the findings of Salleh et al. (2015) that with a well-planned safety culture workplace safety can promote superior employee performance because of the fear of being harmed no more burdens workers. The results corroborate the findings of Hassan and Abdullah (2009) that where employee norms, beliefs, attitudes and behaviours are built on strong safety culture, there would be an improved workplace safety for all. They also corroborate the findings of Zou (2011) and Clarke (2003) that if the cultural norms and values of organisational members are built into safety policies and procedures, and properly implemented, work safety would be achieved.

\section{Relationship between Safety Culture and Management Safety Practices}

The second hypothesis was formulated to establish the link between safety culture and management safety practices. The results of the PLS-SEM show that safety culture is a significant positive predictor of management safety practices in the mining industry in Ghana ( $\beta=0.521 ; \mathrm{t}=11.317 ; \mathrm{p}=0.0001 \mathrm{p}<0.05)$. The beta $(\beta)$ shows that a unit increase in safety culture causes 0.521 increase in management safety practices. These results show that management safety practice is the construct on which safety culture has the largest significant positive effect as compared to all other endogenous constructs in the study (see Table 7) and is, therefore, empirically relevant to improving management safety practices in the mining industry with an effect size of $f^{2}=0.373$. The coefficient of determination between safety culture and management safety practice was $\mathrm{R}^{2}=0.272$, showing that a change in safety culture accounts for $27.2 \%$ change in management safety practices. Thus, safety culture accounts for a large variance in work safety. Management safety practices that are improved as a result of changes in safety culture include the provision of sufficient safety programmes, equipment and safe working conditions, frequent safety inspections, continuous investigation of safety 
problems, quick response to safety concerns and keeping workers informed of hazards.

The above results support the findings of Chen et al. (2017) who found that safety culture promotes proper management of the interplay between the human and technological aspect of the organisation. The results are also in line with the findings of Årstad and Aven (2017) that safety culture promotes acceptable safety practices such as the early identification of hazards, the putting in place of effective controls and the training and empowerment of employees. The results corroborate the findings of Gnoni and Saleh (2017) safety culture allows managers to embark on safety practices such as formulating and implementing strategies for preventing accidents when management detects near-miss events which usually precede major accident events in the future.

\section{Relationship between Safety Culture and Safety Programmes}

Another hypothesis was formulated to establish a relationship between safety culture and safety programmes. The PLS-SEM results indicate that safety culture is a significant positive predictor of safety programmes in the mining industry in Ghana ( $\beta=0.399 ; t=8.226 ; p=0.0001: p<0.05)$. The beta $(\beta)$ shows that a unit change in safety culture causes a 0.399 change in safety programmes. These results show that safety culture has a significant positive effect on safety programmes in the mining industry in Ghana (see Table 7) and is, therefore, empirically relevant to improving safety programmes in the industry with an effect size of $f_{2}=0.190$, signifying medium effect size. The coefficient of determination between safety culture and safety programmes was R2 $=0.159$, showing that a change in safety culture accounts for a $\mathbf{1 5 . 9 \%}$ change in safety programmes. The type of safety programmes that are improved as a result of changes in safety culture includes those that are clear, worthwhile, good, useful and effective in reducing or preventing injuries and accidents. The results support the findings of Zivkovic and Ivanova (2016), Hagge et al. (2016) and Kim et al. (2016). These authors generally argued that in effective safety culture, management could design safety programmes that aim at creating self-sustaining environments with proper knowledge of the causes of occupational accidents.

\section{Relationship between Safety Culture and Co-Worker Safety}

The relationship between safety culture on co-worker safety was also examined in this study. The PLS-SEM results also show that safety culture is a significant positive predictor of co-worker safety in the mining industry in Ghana $(\beta=0.474 ; t=11.144$; 
$\mathrm{p}=0.0001: \mathrm{p}<0.05)$. These results indicate that a unit increase in safety culture causes 0.474 increase in co-worker safety in the mining industry in Ghana (see Table 7). The results imply that safety culture is empirically relevant to improving coworker safety in the industry with an effect size of $f^{2}=0.290$, signifying that safety culture has medium effect size on co-worker safety in the Ghana mining industry. The coefficient of determination between safety culture and co-worker safety was $\mathrm{R}^{2}=0.225$ (see Table 6), showing that a change in safety culture accounts for a $22.5 \%$ change in co-worker safety in the industry. The aspect of co-worker safety that is improved as a result of changes in safety culture include paying attention to and following safety rules and programmes, looking out for others' safety and encouraging others to behave safely. These results corroborate the findings of Pater (2015) that safety culture benefits co-workers by influencing safety behaviours and encouraging shared responsibility.

\section{Relationship between Safety Culture and Supervisor Safety}

A fifth hypothesis was formulated to establish the link between safety culture and supervisor safety. Much like the other four endogenous constructs, the results of the PLS-SEM show that safety culture is a significant positive predictor of supervisor safety in the mining industry in Ghana ( $\beta=0.446 ; t=9.545 ; \mathrm{p}=0.0001$ : $\mathrm{p}<0.05)$. The beta $(\beta)$ shows that a unit increase in safety culture causes 0.446 increase in supervisor safety (see Table 7). The results imply that safety culture is empirically relevant to improving supervisor safety in the industry with an effect size of $f^{2}=$ 0.248 , signifying that safety culture has medium effect size on supervisor safety in the mining industry in Ghana (see Table 7). The coefficient of determination for the relationship was $\mathrm{R}^{2}=0.199$ (see Table 6), showing that a change in safety culture accounts for a $19.9 \%$ change in supervisor safety. The aspect of supervisor safety that is improved include praising and encouraging safe work behaviours, keeping workers informed about safety rules, involving workers in the design of safety goals and training and updating workers on safety issues. These results support the findings of Misnan and Mohammed (2007) that safety culture promotes the efficient and safety supervisory systems in industries that regularly exposed to risk.

\section{CONCLUSIONS AND RECOMMENDATIONS}

The findings from this study indicate that workplace safety can be improved by enhancing the safety culture in the mining industry in Ghana. While not discarding completely, the view that technological malfunctions from defective equipment could cause workplace injuries and accidents, the faulty layout of the plant, 
inadequate safety devices, unsafe storage systems as well as the looming danger of industrial work environment that is continuously characterised by a chunk of hand lift trucks, heavily loaded vehicles, wheel-barrows and electric drop lights which required physical measures such as the wearing of gloves and helmets as postulated by early theorists (Glendon et al., 2006; Seo, 2005; Goetsch, 2005), this study proposes that behavioural factors are equally important in mitigating workplace accidents and injuries, as held by Stemn et al. (2019), Stemn (2018) and Bansah et al. (2016). On this basis, the study recommends that HR managers in the mining industry in Ghana should lay more emphasis on ways that would enhance the safety culture of all employees in the industry. They can do this through the consistent application of safety audit protocols at different parts in the organisation, the effective development of safety goals and policies, the involvement of employees in policy formulation and design, the frequent reaction by managers and safety professionals about safety matters when a proposed budget seems to threaten safety, the availability of a formal budgeting process to give enough resources to support process safety initiatives and the readiness to learn from previous accidents, near misses and non-compliant behaviour. When these are correctly done, there would be an improvement in management safety practices, supervisor safety, safety programmes, co-worker safety, and work safety (in order of priority) which would collectively improve workplace safety in the mining industry in Ghana.

The findings from this study have provided valuable information about safety culture and how it can improve workplace safety, especially from a developing country perspective. The study emphasised safety culture as an important tool for improving the work environment of the mining industry, as evidenced by the results of the PLS-SEM analysis. Much as these results are expected to contribute to knowledge, managerial practice and policymaking, some possible limitations must be considered. The results of this study are not free of bias as the data collected for the study included all potential bias and prejudice of the respondents involved in the study. Notwithstanding the limitations, the results of this study can be used by firms in the mining industry to gain more insight into how safety culture can be used in the struggle against industrial accidents and injuries in Ghana.

\section{REFERENCES}

Amponsah-Tawiah, K., Jain A., Leka, S., Hollis, D., \& Cox, T. (2013). Examining psychosocial and physical hazards in the Ghanaian mining industry and their implications for employees 'safety experience. Journal of Safety Research, 45, $75-84$. 
Amponsah-Tawiah, K., \& Dartey-Baah (2011). Occupational health and safety: Key issues and concerns in Ghana. International Journal of Business and Social Science, 2, $119-126$.

Amponsah-Tawiah, K., \& Mensah, J. (2016). Occupational health and safety and organisational commitment: evidence from the Ghanaian mining industry. Safety and Health at Work, 7(3), 225- 230.

Amponsah-Tawiah, K., Akomeah, O., \& Mensah, J. (2015). Occupational health and safety management and turnover intention in the Ghanaian mining sector. Health and Safety at Work, 7(1), 12-17.

Årstad, I., \& Aven, T. (2017). Managing major accident risk: concerns about complacency and complexity in practice. Safety Science, 91, 114-121.

Aytaç, S., \& Dursun, S. (2012). The effect on employees of violence climate in the workplace. Work, 41, 3026-3031.

Babbie, E. (2007). The practice of social research: International student edition (11th ed.). Australia: Wadsworth Cengage Learning.

Bansah, K. J., Yalley, A. B., \& Dumakor-Dupey, N. (2016). The hazardous nature of small - scale underground mining in Ghana. Journal of Sustainable Mining, 15(1), $8-25$.

Bell, T. (2007). Workplace safety is not just an issue of miners. Business Report. 12, 9-11.

Ceylan, H. (2013). A new approach to occupational accidents: technique of deviation from means. Social and Educational Studies, 5(2), 819 - 830.

Changwon, S. (2016). A study of safety culture assessment framework for process industries and its application to a Bayesian belief network analysis, A Master's thesis, submitted to the Office of Graduate and Professional Studies of Texas A \& M University.

Chen, Y. McCabe, B., \& Hyatt, D. (2017). Impact of individual resilience and safety climate on safety performance and psychological stress of construction workers: A case study of the Ontario construction industry. Journal of Safety Research, 61, 167-76.

Cheyne, A., Tomas, J. M., Cox, S., \& Oliver, A. (1999). Modeling employee attitudes to safety: a comparison across sectors. European Psychologist 1,4-10.

Clarke, S. (2003). The contemporary workforce: Implications for organisational safety culture. Personnel Review, 32(1), 40 - 57.

Cohen. J. (1988) Statistical power analysis for the behavioral sciences: Lawrence Erlbaum Associates Publishers. 
Cooper, D. (2002). A model for understanding and quantifying a difficult concept. Professional Safety, $30-36$.

Doty, D. H., \& Glick, W. H. (1998). Common methods bias: Does common methods variance really bias results? Organisational Research Methods, 1(4), 374-406.

Elgstrand, K. Sherson, D. L. Jørs, E. Nogueira, C. Thomsen, J. F. Fingerhut, M.Burström, L. Rintamäki, H.Apud, E. Coulson, N. McMaster L. \& Clarke E.E. (2017). Safety and health in mining: part 3: issues in occupational health. Occupational Health Southern Africa, 23(5), 18-23.

Fornell, C. G., \& Larcker, D. F. (1981). Evaluating structural equation models with unobservable variables and measurement error. Journal of Marketing Research, 18(1), 39-50.

Geisser, S. (1974). A predictive approach to the random effect model. Biometrika, 61(1), 101-107.

Geller, S. (1994). Ten principles for achieving a total safety culture. Professional Safety, 39(9) 18-24.

Ghana Minerals Commission (2014). Statistical overview of Ghana's mining industry (2010-2013): Accra, Ghana Minerals Commission.

Ghana Minerals Commission (2019). Statistical overview of Ghana's mining industry (2012-2014): Accra, Ghana Minerals Commission.

Glendon, A. I., Clarke, S.G., \& McKenna, E.F. (2006). Human safety and riskmanagement. Boca Raton, FL: CRC/Taylor Francis.

Gnoni, M. G., \& Saleh, J. H. (2017). Near-miss management systems and observability in-depth: Handling safety incidents and accident precursors in light of safety principles. Safety Science, 91, 154-167.

Goetsch, D. L. (2005). Occupational safety and health for technologists, engineers, and managers. (5th ed.) New Jersey: Pearson Prentice Hall.

Guldenmund, F. W. (200o). The nature of safety culture: A review of theory and research. Safety Science, 34(1), 215-257.

Haenlein, M. \& Kaplan, A. M. (2004), “A beginner's guide to partial least squares analysis”, Understanding Statistics, 3(4), 283-297.

Hagge, M., McGee, H., Matthews, G., \& Aberle, S. (2016). Behavior-based safety in a coal mine: the relationship between observations, participation, and injuries over a 14-year period. Journal of Organisational Behaviour Management, 37(1), 1-12. 
Hair Jr, J. F., Sarstedt, M., Hopkins, L., \& Kuppelwieser, V. G. (2014). Partialleast squares structural equation modeling (PLS-SEM). European Business Review, 4(2), 23-34.

Hair, J. F., Risher, J. J., Sarstedt, M., \& Ringle, C. M. (2019). When to use and how to report the results of PLS-SEM. European Business Review, 4(2), 1- 14.

Hassan, A. \& Abdullah, N.A.C. (2009). Management practice in safety culture and its influence on workplace injuries: An industrial study in Malaysia. Disaster Prevention and Management, 18(5), $470-477$.

Hayes, B., Perander, J., Smecko, T., \& Trask, J. (1998). Measuring perceptions of workplace safety: Development and validation of work safety scale. Journal of Safety Research, 29, 145-161.

Heinrich, H. W. (1931). Industrial accident prevention. New York: McGraw-Hill.

Henseler, J., Ringle, C. M., \& Sarstedt, M. (2015). Anew criterion for assessing discriminant validity in variance-based structural equation modeling. Journal of the Academy of Marketing Science, 43(1), 115-135.

Jöreskog, K. G. (1971). Simultaneous factor analysis in several populations. Psychometrika, 36(4), 409-426.

Kim, Y., Park, J., \& Park, M. (2016). Creating a culture of prevention in occupational safety and health practice. Safety and Health at Work, 7(2), 89-96.

Kock, N., \& Lynn, G. (2012). Lateral collinearity and misleading results in variancebased sem: an illustration and recommendations. Journal of the Association for Information Systems, 13(7), $23-43$.

Kyeremateng-Amoah, E., \& Clarke, E. E. (2015). Injuries among artisanal and smallscale miners in Ghana. International Journal of Environmental Research and Public Health, 12(9), 10886 - 10896.

Long, R.N., Sun, S., \& Neitzel, R. (2015). Injury risk factors in a small-scale gold mining community in Ghana's Upper East Region. International Journal of Environmental Research and Public Health, 12(8), 8744-8761.

Lu, C. S., \& Tsai, C. (2010). The effect of safety climate on seafarers' safety behaviors in container shipping. Accident Analysis and Prevention, 42, 1999-2006.

Mat Roni, S. (2014). Introduction to SPSS. Edith Cowan University, SOAR Centre, Australia.

Misnan, M. S. \& Mohammed, A.H. (2007). Development of safetyculture in the construction industry: A strategic framework. Conference on sustainable building, South East Asia. 
Pater, R. (2015). Toward global-class safety. Journal of Professional Safety, 6o(1), 18.

Podsakoff, P. M., MacKenzie, S. B., \& Podsakoff, N. P. (2012). Sources of method bias in social science research and recommendations on how to control it. Annual Review of Psychology, 63, 539-569.

Pronovost, P., \& Sexton, B. (2005). Assessing safety culture: Guidelines and recommendations. Quality and Safety in Health Care, 14, 231- 233.

Raithel, S., Sarstedt, M., Scharf, S., \& Schwaiger, M. (2012). On the value relevance of customer satisfaction. Multiple drivers and multiple markets. Journal of the Academy of Marketing Science, 40(4), 509-525.

Reason, J. T. (1994). A systems approach to organisational error. Proceedings of the 12th Triennial Congress of the International Ergonomics Association, 1, 94 - 96.

Rezaei, S. (2015). Segmenting consumer decision-making styles (CDMS) toward marketing practice: A partial least squares (PLS) path modeling approach. Journal of Retailing and Consumer Services, (22), 1-15.

Salleh, M, Yulia, A, F. M., Noorazman, M. A., \& Roslan, U. A. A. (2015). Safety culture and its contributing factors in manufacturing workplace in Malaysia. IJABER, 13(7), 5819-5827

Sehgal, B. (2012). Nuclear safety in light water reactors, severe accident phenomenology, Academic Press.

Seo, D-C. (2005). An explicative model of unsafe work behavior. Safety Science, 43(3), 187-211.

Standing, A. (2014). Ghana's extractive industries and community benefit sharing: The case for cash transfers. Resources Policy, 40, 74-82.

Stemn, E., Bofinger, C., Cliff, D., \& Maureen, E. (2019). Investigating the maturity of incident investigations of the Ghanaian mining industry and its effect on safety performance. Safety, $1-25$.

Stemn, S. (2018). Analysis of injuries in the Ghanaian mining industry and priority areas for research. Safety and Health at Work, 1-15.

Stewart, P., Bezuidenhout, A., \& Bischoff, C. (2020). Safety and health before and after Marikana: subcontracting, illegal mining and trade union rivalry in the South African mining industry. Review of African Political Economy, 47(163), 27-44.

Stone, M. (1974). Cross-validatory choice and assessment of statistical predictions. Journal of the Royal Statistical Society: Series B (Methodological), 36(2), 111-133. 
Tucker, S., Chmiel, N., Turner, N., Hershcovis, M. S., \& Stride, C. B. (2008). Perceived organisational support for safety and employee safety voice: The mediating role of co-worker support for safety. Journal of occupational health psychology, 13(4), 319-330

U.S. Nuclear Regulatory Commission (2011). Final safety culture statement. NRC-2010o282. Federal Register, 76, 34773-34778.

Umar-Faruk, F., Asumeng, M., \& Kingsley, N. (2015). The impact of safety climate on safety performance a gold mining company in Ghana. International Journal of Management Excellence, 5(1), 556 - 566.

Zivkovic, S., \& Ivanova, T. (2016). Organisational culture as one of the main factors for successful safety management. Serbian Journal of Management, 11(1), 69-80.

Zou, P. X. W. (2011). Fostering a strong construction safety culture. Leadership and Management in Engineering, 11, 11 - 22. 